\title{
THE MODEL OF THE INTELLIGENCE SYSTEM FOR THE ANALYSIS OF QUALIFICATIONS FRAMEWORKS OF EUROPEAN COUNTRIES
}

\author{
Viacheslav Osadchyi, Kateryna Osadcha, Volodymyr Eremeev \\ Melitopol State Pedagogical University named after Bohdan Khmelnytskyi, \\ Melitopol, Zaporizhzhia region, Ukraine \\ poliform55@gmail.com
}

\begin{abstract}
The paper presents the model of the intelligence system for carrying out the comparative analysis of qualifications frameworks of European Countries. The conceptual construct of the model consists of national qualifications frameworks, qualification levels and descriptors such as Knowledge, Skills etc. Each notion is matched with a set of semantic elements which are determined in the field that characterizes all the components of European frameworks. The model allows a user to determine a quantitative measure of correlation between frameworks and qualification levels in different countries.

The proposed model of the intelligent system is based on the concept of knowledge base application in the process of solving various tasks, depending on user needs. Such a system is, as a matter of fact, an expert system. At present there is not any universal body of logics and mathematics which could meet requirements of any IS developer. Our model is developed on the basis of special knowledge related to the classification of European education levels in the context of the Bologna process. Copyright (C) Research Institute for Intelligent Computer Systems, 2017. All rights reserved.
\end{abstract}

Keywords: the Bologna process, descriptor, intelligence system, artificial intelligence, qualification, set, model, qualification level, qualifications framework.

\section{INTRODUCTION}

The development of higher education in Europe largely depends on the Bologna process [1]. The primary purpose of this process was to create the European space for higher education (ESHE) by 2010 with its further improvement by 2020. The ESHE unites European nations which agreed to implement the Bologna declaration (1999) and further decisions made in Prague (2001), Berlin (2003), Bergen (2005), and London (2009). These decisions coordinate the higher education reform by implementing the three-stage certification system (Bachelor, Master and $\mathrm{PhD}$ ), ensuring transparency of the education content by providing credits of the European Credit Transfer and Accumulation System, creating common European understanding of the education quality and introducing higher education qualifications frameworks [2].

The system of higher education of European countries [3-5] is being actively reformed. Integration in the Bologna process promotes European collaboration of universities and enables young people to be guided when choosing popular specialities. In this respect the development of National qualifications frameworks in Europe [5] serves as an important link in the development of the Bologna process. In many regulations it has been noted that higher education reform does not imply any unification of the higher education systems in different countries. Vice versa, each country can keep its national traditions, heritage and culture while organizing the educational process. Comparison of National education frameworks of different countries which have been developed indicates that in general their contents are close to the European Qualifications Framework (EQF).

The common component of all European frameworks is a qualification level, in spite of the fact that the number of levels differs across countries. If the number of levels in the EQF is 8, according to the National Qualifications Framework of Ukraine (NQFU) the number of levels is 10 , in France and Germany it is equal to 8 , in the Russian Federation it is equal to 9, etc. So, the development of comparison methods of qualification levels in different countries is of great practical importance. The present research deals with the development of the information system model, by means of which it will be possible to carry out a comparative analysis of qualification levels in frameworks of different European countries. 


\section{PROBLEM STATEMENT}

Creation of artificial intelligence as a new scientific field [6] has stimulated the development of modern intelligent systems and intelligent information technology [7], that have found practical application in almost all spheres of human activity for the purpose of production automation [8], improvement of the management and training effectiveness, development of ontologies, the Knowledge Base [9, 10] and in other cases. The situation considered in the $I S$ is simulated with the use of modern mathematical methods $[8,11]$.

The development of the $I S$ begins with the situation simulation and further development of the set of software, linguistic, logical and mathematical tools. Since the class of problems in the area of human intellectual activity is huge, it is needless to rely on the creation of the $I S$ unified theory. The basic $I S$ elements were developed in the middle of the last century (Wiener, von Neumann, Turing and others) [7]. The theory of artificial intelligence is being constantly updated and developed $[12,13]$. The promising results have been achieved in some research papers [13-15]. The use of $I S$ s opens great prospects in the field of education that cannot be overestimated under conditions of ever-increasing information flow, reconsideration of old knowledge and appearance of new one. For this reason, the theoretical research in this field and the development of new ISs are relevant tasks.

The characteristics and qualities of $I S \mathrm{~s}$ are completely determined by the form of knowledge representation and the knowledge model. The research data confirms that each school develops its own methods of $I S$ organization. One of the $I S$ concepts designed to support the functioning of national qualifications frameworks is presented in our work [16]. The methodological approaches to the $I S$ implementations are to a large extent much the same and are reduced to the following steps:

- definition of basic concepts and their attributes,

- identification of the source and target information,

- structurization of concepts according to their hierarchy,

- elicitation of connections between concepts,

- strategy determination for making decisions,

- description of glossary, thesaurus and key phrases,

- development of mathematical model,

- IS implementation on the basis of computer tools.

The general scheme and structure of $I S \mathrm{~s}$ are usually depicted in the form of archetypes, cognitive schemes, graphs, sets, and other forms. At the stage of creation of $I S \mathrm{~s}$ it is useful to choose a software environment that will ensure the task execution. Not so long ago logic languages such as Prolog and Lisp were used for the $I S$ development. At present objectoriented languages and special software shells are usually applied.

The main difficulty of the $I S$ development is related to the choice of the mathematical model that has to provide a flexible connection between all elements of the system, so the careful description of the conceptual apparatus of the model is of crucial importance.

The purpose of our work is mathematical modeling of the $I S$ designed for the comparative analysis of the conceptual apparatus in the qualifications frameworks of the European countries. To achieve the purpose it is necessary to solve the following tasks:

- to formulate the conceptual construct of the $I S$ in the investigated subject field $Q$,

- to select the scheme of interaction between the main elements of the $I S$,

- to create a mathematical model,

- to propose an algorithm for finding probabilistic characteristics of the comparative analysis results.

\section{CONCEPT CONSTRUCT AND TASK FORMULATION}

We denote the National framework of qualifications by $P$, where index $U=1,2, \ldots, R$ codes of one of $R$ European countries joined to the Bologna process. We combine notions $P^{U}$ in group $\{P\}=\left\{P^{l}, P^{2}, \ldots, P^{U}, \ldots, P^{R}\right\}$. The name of the notion is any identifier. Further, we assign index 1 to the National qualifications framework of Ukraine, index 2 - to the EQF, index 3 - to the National qualifications framework of the Russian Federation and so on. The qualifications framework in a particular country is characterized by several levels [5]. For example, the EQF comprises eight qualification levels with indices $k=1,2, \ldots 8$ [4], the National qualifications framework of Ukraine and the National qualifications framework of the Russian Federation incorporate ten qualification levels with indices $n=0,1,2, \ldots 9$. Every notion $P^{U}$ from group $\left\{P^{U}\right\}$ is confronted with a subgroup of several notions of the second level related to the qualification levels; for this reason the following symbols are introduced:

$$
\left\{P^{U}\right\}=\left\{P^{U 0}, P^{U 1}, P^{23}, \ldots\right\}, U=1,2, \ldots R,
$$

Explanations of the symbols in (1) may be given by the example of the National qualifications framework of Ukraine and the European qualifications framework: 
- the notion of the National qualifications framework of Ukraine is denoted by $P^{l}$; the subgroup of notions related to the qualification levels comprises 10 notions of the second nesting level with indices from 0 to $9\left(P^{l 0}, P^{l 1}, \ldots, P^{l 9}\right)$;

- the notion of the European qualifications framework is denoted by $P^{2}$; in this case the subgroup of notions which characterize the qualification level comprises 8 elements $P^{21}, P^{22}, \ldots$, $P^{28}$, where indexation begins with 1 .

In turn, any notion for the $i$-qualification level $P^{U I}$ is characterized by "Knowledge", "Skills" and several other descriptors. They represent the third nesting level notions. We denote the descriptors by $P^{U i}{ }_{k}$. Thus, every notion of the second nesting level is determined by the subgroup of notions of the further nesting level of elements $P^{U i}{ }_{k}$ in accordance with denotations:

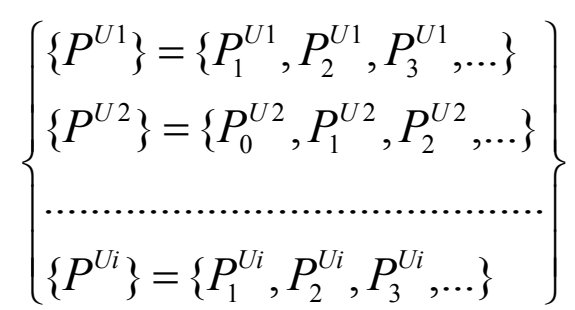

A hierarchical tree of notions is presented in Fig. 1.

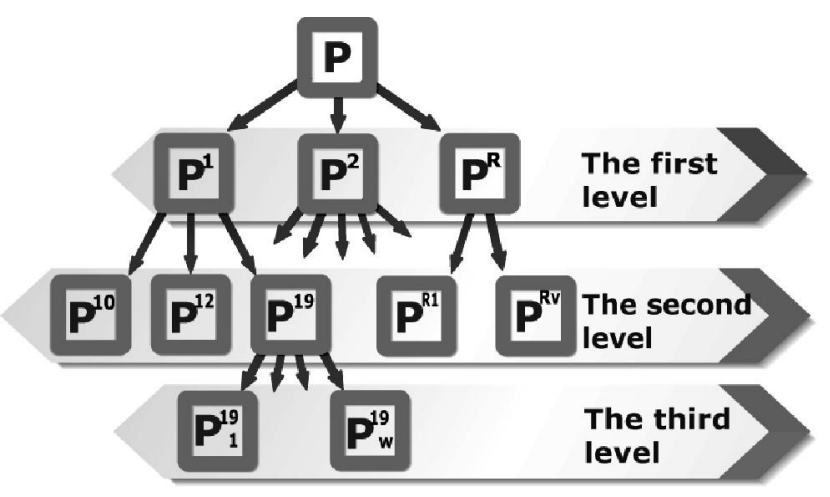

Fig. 1 - A hierarchical tree of notions

The semantic content, referring to the specific concept of $P^{U i}{ }_{k}$ for fixed values $U, i$ and $k$ is represented by information in the text form. For example, the content of the concept of $P^{12}{ }_{1}$ (the "Knowledge" descriptor, the index $k=1$, the second qualification level, the index $i=2$ of the NQFU, the index $U=1$ ) is revealed as follows [17]:

"Basic factual knowledge acquired in the process of training and (or) work. Understanding of the basic (general) processes in training and (or) labour activity".

The similar notion of $P^{32}{ }_{l}$ for the NQFR (indices $k=1, i=2, U=3$ ) has the similar meaning [18]:
"Specific knowledge, knowledge of normative technological documentation within the scope of standard problem solving; knowledge which is necessary to organize their own work".

In the case of the EQF, the textual side of the notion of $P^{22}{ }_{1}$ is: "Elementary actual knowledge in the field of work or study". The concept for the third level of $P^{23}{ }_{1}$ of the same framework is characterized as "Knowledge of facts, principles, processes and general concepts in the field of work or study".

A number of studies have dealt with the study of qualifications frameworks. In paper [3] the conceptual apparatus related to the new generation of educational programs is examined in detail, and the comparative analysis of the implementation of the Bologna process in Ukraine and Poland is carried out. Based on the study of the qualification frameworks of the Russian Federation, Germany and the United Kingdom, the author of [19] draws specific conclusions on the organization of the educational process in Russia in accordance with the provisions of the Bologna Process. The concept of an intellectual information and cognitive support system for the functioning of the national qualifications framework is set forth in [15]. As far as we know, intellectual systems are not available for conducting an automated comparative analysis of the national qualifications frameworks. The theoretical basis for solving such a problem is described in the works of Ch. Hoare, R. Floyd, A. Church, H. Curry, H. Barendregt, J. Backus, D. Scott, F. Luger, A. Sokolov, V. Lytvyn and other scientists. In particular, it seems interesting to use semantic technologies and reference ontologies.

When comparing various decision-making methods with ISS and capabilities of modern knowledge-based mathematical models, the author of [10] concludes that the creation of methods for the functioning of decision support systems for the comparative analysis of the competency levels of frameworks of different countries using ontologies is an actual problem. Its solution is connected with the analysis of the semantic content of the text. Similar issues have been considered in many works. For example, the determination of the semantic similarity between two sets of words related to two different concepts occurs in web-development, targeted advertising, and in other cases [20]. In [21], the semantic similarity between natural language terms was studied using WordNet as the main reference ontology and between medical terms using the MeSH ontology. The combined method for measuring the semantic similarity of words was proposed in [22]. The similar approach was used for the comparative analysis of texts [23].

Certain difficulties are encountered while using modern semantic technologies, since in our case we 
are not talking about the external similarity or similarity of textual materials, but about their semantic contents. We agree with the author of [24] that the modern theory of recognizing the text meaning is far from its completion. Indeed, we return to the textual description of the two concepts $P^{13}$, and $P^{23}{ }_{1}$, corresponding to the "Knowledge" descriptor of the third level in the NQFU and the EQF. The meanings of the contents of $P^{13}{ }_{1}$, and $P^{23}{ }_{1}$ in their functional purpose are close to each other. However, a formal analysis of these concepts, performed in the machine version using semantic technologies, can give a completely different result, since the textual description of $P^{12}{ }_{1}$ contains 24 words, and $P^{22}{ }_{1}$ has 10 words, and the only word "knowledge" is common to these concepts (without in, the and or).

In this paper, we refuse to clarify the meaning of a particular notion, presented in the text form and suggest moving to another level of presentation of the semantic content of the analyzed object. We introduce a universal set $V$ consisting of elementary units of semantic information $v_{i} \in V, i=1,2, \ldots s$, where $s$ is a number of elements $\mathrm{v}_{i}$, determining the cardinality of the set $V$. We suppose that the semantic content and its numbers are completely sufficient for an exhaustive description of the notions related to the subject domain $Q$, consisting of the qualifications frameworks of the Bologna process participants. The unit element $v_{i}$ will be associated with information that is not subject to further fragmentation and uniquely determines its content. As an example, some of the elements of set $V$, compiled by an expert on national frameworks of qualification levels are presented in Table 1.

Table 1. An example of description of several unit elements of the set $V$ and their measures $\mu$ (vi) for the "Knowledge" descriptor

\begin{tabular}{|l|c|c|}
\hline Description of the unit element $v_{1}^{U i}$ & Code & $\mu(\mathrm{vi}))$ \\
\hline $\begin{array}{l}\text { Basic general knowledge about } \\
\text { himself/herself }\end{array}$ & 1 & 2 \\
\hline $\begin{array}{l}\text { Basic general knowledge about the } \\
\text { environment }\end{array}$ & 2 & 2 \\
\hline $\begin{array}{l}\text { Comprehension of basic cause-effect } \\
\text { relationships }\end{array}$ & 3 & 2 \\
\hline $\begin{array}{l}\text { Comprehension of simple notions } \\
\text { about the environment }\end{array}$ & 8 & 2 \\
\hline $\begin{array}{l}\text { Comprehension of } \\
\text { fundamentals }\end{array}$ & 9 & 2 \\
\hline $\begin{array}{l}\text { Basic evidential knowledge received } \\
\text { in the training process }\end{array}$ & 10 & 1 \\
\hline $\begin{array}{l}\text { Knowledge of particular principles in } \\
\text { the field of study }\end{array}$ & 12 & 2 \\
\hline \multicolumn{1}{c}{.......................... } & $\ldots$. & $\ldots \ldots$ \\
\hline $\begin{array}{l}\text { Advanced conceptual and } \\
\text { methodological knowledge at the } \\
\text { interface between subject fields }\end{array}$ & 50 & 4 \\
\hline
\end{tabular}

Table 1 consists of 50 unit elements $v_{i}$ with the indication of their codes and measures in the form of a number. When forming Table 1 the expert adhered to the following rules:

A) The set of unit elements in Table 1 consists of a minimum number of semantic unit elements providing a comprehensive description of the "Knowledge" descriptor in the European frameworks.

B) All the unit elements $v_{i}$ from Table 1 satisfy the orthogonality condition,

$$
v_{i} \cap v_{j}=\varnothing \text { if } i \neq j
$$

which indicates the independence of these elements from each other.

C) The quantitative measure of each element characterizes the degree of its significance in the overall score of the notion under consideration. The sum of the measures for estimating the measures $\mu\left(v_{i}\right)$ for elements belonging to the "Knowledge" descriptor is 100 points.

At first glance, the requirement of orthogonality (3) may seem too rigid. In reality, this is not the case. We suppose that the restriction (3) is removed and two elements with indices $i$ and $j$ are not orthogonal, that is, $v_{i} \cap v_{j}=v_{k} \neq \varnothing$. In this case, we exclude the elements $v_{i}$ and $v_{j}$ from the universal set $V$, and we supplement it with three elements $\left.v_{k}=v_{i} \cap v j, v_{i}\right)\left(v_{i} \cap v_{j}\right)$ and $v_{j} \backslash\left(v_{i} \cap v_{j}\right)$, which obviously satisfy the orthogonality condition (3). Similar tables compiled for all descriptors ensure that the universal set $V$ is filled. The set $V$ will be considered complete in the sense that the semantic content of each of the concepts $P^{U}, P^{U i}, P^{U i}{ }_{k}$ can be defined by subsets of elements $V$. We denote these subsets by $F^{U}, F^{U i}, F^{U i}{ }_{k}$ respectively.

The content of various descriptors ("Knowledge", "Skills", etc.), refers to different characteristics of frameworks, therefore the sets $F^{U i}{ }_{k}$ are independent for fixed values $U$ and $i$. The scheme for the introduced notions in Fig. 1 reflects the relations between the sets $F^{U}, F^{U i}, F^{U i}{ }_{k}$. Comparison of the qualifications frameworks of the two countries $A$ and $B$ can be carried out using several queries, for example:

- the content of the country $A$ framework is compared directly with the content of the country $B$ framework;

- the content of the country $A$ framework is compared with the content of the country $B$ framework in terms of the EQF [25];

- the content of one of the country $A$ framework level is compared with the content of one of the country $B$ framework level;

- the analysis of the correspondence of qualification levels of the country $A$ framework with 
the level or qualification levels of the country $B$ is carried out in terms of the EQF [25];

- comparison of qualification levels of different countries is carried out only on the basis of one of the parameters, for example, on the basis of "Knowledge" or "Skills" descriptors;

- comparison of qualification levels of different countries is carried out only on the basis of one of the parameters, for example, on the basis of "Knowledge" or "Skills" in terms of the European qualifications framework [25].

In order to carry out a comparative analysis in the listed areas, it is necessary to determine the numerical measure of the semantic content of each notion, select a criterion for the correspondence of notions related to different frameworks, and develop a computational algorithm.

\section{CHOICE OF SET MEASURES $P^{U}, P^{U I}, P_{K}^{U I}$}

Quantitative analysis involves using a measurement unit. We introduce a notion of measure $\mu\left(v_{i}\right)$ for a single element $v_{i}$. As a measure $\mu\left(v_{i}\right)$ we take a real number, that characterizes the amount of useful information in one element $v_{i}$. A measure amount is set by the expert. Measures for some elements are given in Table 1.

We denote the set of subsets $S_{i}$ of all conceivable combinations of elements of the set $V$ and supplement it with the empty set $\varnothing$ by $\Omega$.

$$
\Omega=\left\{0, S_{i}, S_{j}, \ldots\right\},
$$

We assume that general operations with its components are performed on the set $\Omega$. In this case, there are obvious nesting relations within the sets $F^{U}, F^{U i}, F^{U i}$ :

$$
F_{k}^{U i} \subset F^{U i} \subset F^{U}, F_{k}^{U i} \cap F_{m}^{U i}=\varnothing,(k \neq m) .
$$

The example of the set $F^{U i}$ for the classification level and the framework $U$ is:

$$
F^{U i}=\bigcup_{m} v^{U i}{ }_{m}
$$

and the measure of the set $F^{U i}$ is equal to the total of unit elements measures belonging to it:

$$
\mu\left(F^{U i}\right)=\sum_{m} \mu\left(v^{U i}{ }_{m}\right)
$$

Similarly, all the sets $F^{U}, F^{U i}, F^{U i}{ }_{k}$ are uniquely defined on the universal set $V$, therefore with known measures for the unit elements $\mu\left(v_{i}\right)$ it becomes possible to calculate their measures $\mu\left(F^{U}\right), \mu\left(F^{U i}\right)$, $\mu\left(F_{k}^{U i}\right)$.
Within the framework of the theory of sharp sets, the measure of any set is equal to the sum of measures of the unit elements $v_{k}$ belonging to it. By definition, the universal set $V$ is discrete. It is hard to expect that in reality a "house" referring to the elements of the set $P$ can be built from a combination of its unit elements, which are a kind of "building blocks", with absolute precision. In the strict sense, instead of the formulae (5), (6) the approximate expressions are to be written as:

$$
\begin{gathered}
F^{U i} \approx \bigcup_{m} v^{U i}{ }_{m}, \\
\mu\left(F^{U i}\right) \approx \sum_{m} \mu\left(v^{U i}{ }_{m}\right)
\end{gathered}
$$

Application of the fuzzy set theory allows us to move from the approximate expressions (7) and (8) to the precise formulations. We denote the probability that the unit elements $v^{U i}{ }_{m}$ belong to the set $F^{U i} \supset \Omega$ by $\alpha^{U i}{ }_{m}$. Then, instead of the formula (8), which is true in the case of a crisp set, it has to be written as:

$$
F^{U i}=\bigcup_{m} \alpha_{m}^{U i} v^{U i}{ }_{m}
$$

The measure of the set $\mathrm{F}^{U i}$ in this case is determined by the formula:

$$
\mu\left(F^{U i}\right)=\sum_{m} \alpha_{m}^{U i} \mu\left(v^{U i}\right),
$$

The measure of the set $F_{k}^{U i} \subset F^{U i} P^{U i}{ }_{k}$ is equal to

$$
\mu\left(F_{k}^{U i}\right)=\sum_{m} \alpha_{k m}^{U i} \mu\left(v^{U i}{ }_{k m}\right)
$$

where $\alpha^{U i}{ }_{k m}$ is the probability that $v^{U i}{ }_{k m} \in F^{U i}{ }_{k}$.

Similarly, the total measure of the set $P^{U}$ for the country qualifications framework may be expressed by the index $U$ through unit elements $v_{m}^{U}$ :

$$
\mu\left(F^{U}\right)=\sum_{m} \alpha_{m}^{U} \mu\left(v_{m}^{U}\right)
$$

where $\alpha_{m}^{U}$ is the probability that $v^{U}{ }_{m} \in F^{U}$.

If $\mu\left(F^{U i}{ }_{k}\right)$ or $\mu\left(F^{U i}\right)$ are known, then for the calculation of $\mu\left(F^{U i}\right)$ and $\mu\left(F^{U}\right)$ the following formulae can be used:

$$
\begin{aligned}
& \mu\left(F^{U i}\right)=\sum_{m} \beta_{m}^{U i} \mu\left(F_{m}^{U i}\right), \\
& \mu\left(F^{U}\right)=\sum_{m} \beta^{U m} \mu\left(F^{U m}\right),
\end{aligned}
$$


where $\beta_{m}^{U i}$ is the probability that $F_{m}^{U i} \subset F^{U i}$ and $F^{U m} \subset F^{U}$

When substituting (10) for (14) and (11) for (13), the following formulae are obtained:

$$
\begin{aligned}
& \mu\left(F^{U}\right)=\sum_{i} \beta^{U i} \sum_{m} \alpha_{m}^{U i} \mu\left(F_{m}^{U i}\right), \\
& \mu\left(F^{U i}\right)=\sum_{k} \beta_{k}^{U i} \sum_{m} \alpha_{k m}^{U i} \mu\left(v^{U i}{ }_{k m}\right),
\end{aligned}
$$

From the equations (11) and (15) we obtain the third expression for the calculation of the measure of the set $F^{U}$ :

$$
\mu\left(F^{U}\right)=\sum_{i} \beta^{U i} \sum_{k} \alpha_{k}^{U i} \sum_{m} \alpha_{k m}^{U i} \mu\left(v^{U i}{ }_{k m}\right),
$$

\section{ADEQUACY OF THE MATHEMATICAL MODEL}

The formulae (11)-(17) allow us to calculate:

- the measure of any qualification level of a general framework for a fixed parameter ("Knowledge", "Skills" and others), the formula (11);

- the measure of any qualification level of a general framework for all of the level parameters ("Knowledge", "Skills" and others), the formulae (10), (13) or (16);

- the measure of any qualifications framework, the formulae (12) or (14) or (15) or (17).

Values of probability factors $\alpha^{U i}{ }_{k m}, \alpha^{U i}, \alpha_{m}^{U}$, $\beta^{U i}{ }_{m}, \beta^{U i}$ and measures of elementary units $\mu\left(v_{m}\right)$ are set by experts. Therefore, calculation results $\mu\left(F^{U i}\right)$ according to the formula (10) may differ from the values calculated according to the formulae (13) or (16). Values $\mu\left(P^{U}\right)$, calculated by the formulae (12), (14), (15), (17) also may vary. This fact can be used for the model adequacy evaluation. We denote the measures, calculated by the formulae (10), (13) and (15) by $\mu_{1}, \mu_{2}$ and $\mu_{3}$, and the average value $\left(\mu_{1}+\mu_{2}+\mu_{3}\right) / 3$ by $\mu$. The average standard deviation $\delta(\mu)$ of the set $\mu\left(F^{U i}\right)$ equals

$$
\delta(\mu)=\sqrt{\left(\mu_{1}-\mu\right)^{2}+\left(\mu_{2}-\mu\right)^{2}+\left(\mu_{3}-\mu\right)^{2}} / 3
$$

The relative average standard deviation $\delta_{0}(\mu)$ of the measure $\mu\left(P^{U i}\right)$ equals:

$$
\delta_{0}(\mu)=\delta(\mu) / \mu
$$

To evaluate the determination accuracy of the measure $\mu\left(P^{U}\right)$ we denote the values calculated according to the formulae (12), (14), (15) and (17) by $v_{1}, v_{2}, v_{3}$, and $v_{4}$, and the average value $\left(v_{1}+v_{2}+v_{3}\right.$, $\left.+v_{4}\right) / 4$ by $v$. The average standard deviation $\delta(v)$ and the relative average standard deviation $\delta_{0}(v)$ of the measure $\mu\left(F^{U}\right)$ will be equal to

$$
\begin{gathered}
\delta(v)=\sqrt{\left(v_{1}-v\right)^{2}+\left(v_{2}-v\right)^{2}+\left(v_{3}-v\right)^{2}+\left(v_{4}-v\right)^{2}} / 4 \\
\delta_{0}(v)=\delta(v) / v
\end{gathered}
$$

The formulae (18)-(21) allow us to estimate the inaccuracy of measure predictions for the notions $F^{U i}$ and $F^{U}$.

\section{ALGORITHM FOR CARRYING OUT THE ANALYSIS}

The procedure for carrying out the comparative analysis can be represented in the form of the following stages:

- creating the universal set $V$ of unit elements $v_{i}$ which provide creation of subsets:

- coding the universal set $V$ with specifying keys and measures $\mu\left(v_{i}\right)$ of each element;

- compiling the tables of belonging probabilities of the elements $\mathrm{v}_{\mathrm{i}}$ in all the sets that correspond to the notions that are shown in Fig. 1;

- determining the probabilities of derived notions occurrence in parental notions, corresponding to the hierarchical tree in Fig. 1;

- carrying out calculations using the formulae (10)-(17);

- analyzing an expert estimate range using the formulae (18)-(21).

The implementation of the proposed algorithm will require the collaboration of a large number of experts from different countries. The process of forming the set $V$ provides favorable conditions for the development of tools in the form of a set of standardized elementary notions that can be used later both in describing notions and in conducting a comparative analysis of notions using ISS.

As an example, we compare the sets $F^{1 i}{ }_{1}$ and $F^{2 i}{ }_{1}$ (the "Knowledge" descriptor) that characterize the qualification levels of the NQFU and the EQF. In Table 1 the part of the elements $v_{m}$ of the universal set $V$ referring to the "Knowledge" descriptor is presented.

Measures of sets $\mathrm{F}^{1 i}{ }_{1}$ and $\mathrm{F}^{2 i}{ }_{1}$ are calculated by the formula (11):

$$
\begin{aligned}
& \mu\left(P^{1 i}{ }_{1}\right)=\sum_{m} \alpha_{1 m}^{1 i} \mu\left(v^{1 i}{ }_{1 m}\right) \\
& \mu\left(P^{2 i}{ }_{1}\right)=\sum_{m} \alpha_{1 m}^{2 i} \mu\left(v^{2 i}{ }_{1 m}\right)
\end{aligned}
$$

Expert estimates of set membership probabilities of single units $\alpha^{U i}{ }_{1 m}$ from Table 1 to sets $F^{U i}{ }_{1}$ for the first levels of the NQFU and EQF are presented in Tables 2 and 3. 
Table 2. Set membership probabilities of unit elements of Table 1 for the "Knowledge" descriptor for sets $F^{10}{ }_{1}, F^{11}, F_{1}^{12}, F^{13}{ }_{1}$ of the NQFU

\begin{tabular}{|c|c|c|c|c|}
\hline \multirow{2}{*}{$\begin{array}{c}\text { Codes } \\
\mathrm{v}_{\mathrm{m}}\end{array}$} & \multicolumn{4}{|c|}{ Sets of the NQFU } \\
\cline { 2 - 5 } & $F^{10}{ }_{1}$ & $F^{11}{ }_{1}$ & $F^{12}{ }_{1}$ & $F^{13}{ }_{1}$ \\
\hline$\ldots$ & $\ldots \ldots$ & $\ldots \ldots$ & $\ldots \ldots$ & $\ldots \ldots$ \\
\hline 8 & $\alpha^{10}{ }_{18}=0$ & $\alpha^{11}{ }_{18}=1,0$ & $\alpha^{12}{ }_{18}=1,0$ & $\alpha^{13}{ }_{18}=1,0$ \\
\hline 9 & $\alpha^{10}{ }_{19}=0$ & $\alpha^{11}{ }_{19}=1,0$ & $\alpha^{12}{ }_{19}=1,0$ & $\alpha^{13}{ }_{19}=1,0$ \\
\hline 10 & $\alpha^{10}{ }_{1 / 10}=0$ & $\alpha^{11}{ }_{1 / 10}=0$ & $\alpha^{12}{ }_{1 / 10}=1$, & $\alpha^{13}{ }_{1 / 10}=0$, \\
& & & 0 & 9 \\
\hline 12 & $\alpha^{10}{ }_{1 / 12}=0$ & $\alpha^{11}{ }_{1 / 12}=0$ & $\alpha^{12}{ }_{1 / 12}=1$, \\
& & & $\alpha^{13}{ }_{1 / 12}=1$, \\
$\ldots$ & $\ldots \ldots$ & $\ldots \ldots$ & $\ldots \ldots$ & $\ldots \ldots$ \\
\hline
\end{tabular}

Table 3. Set membership probabilities of unit elements of Table 1 for the "Knowledge" descriptor for sets $F_{10}^{10}, F_{1}^{11}, F^{12}, F_{1}^{13}$ of the EQF

\begin{tabular}{|c|c|c|c|c|}
\hline \multirow{2}{*}{$\begin{array}{c}\text { Codes } \\
v_{m}\end{array}$} & \multicolumn{4}{|c|}{ Sets of the EQF } \\
\cline { 2 - 5 } & $F^{21}{ }_{1}$ & $F^{22}{ }_{1}$ & $F^{23}{ }_{1}$ & $F^{24}{ }_{1}$ \\
\hline$\ldots$ & $\ldots \ldots$ & $\ldots \ldots$ & $\ldots \ldots$ & $\ldots \ldots$ \\
\hline 8 & $\alpha^{21}{ }_{18}=0$ & $\alpha^{22}{ }_{18}=0,5$ & $\alpha^{23}{ }_{18}=0,5$ & $\alpha^{24}{ }_{18}=0,5$ \\
\hline 9 & $\alpha^{21}{ }_{19}=0$ & $\alpha^{22}{ }_{19}=0,5$ & $\alpha^{23}{ }_{19}=0,5$ & $\alpha^{24}{ }_{19}=0,5$ \\
\hline 10 & $\alpha^{21}{ }_{1 / 10}=0$ & $\alpha^{22}{ }_{1 / 10}=0$ & $\alpha^{23}{ }_{1 / 10}=1,0$ & $\alpha^{24}{ }_{1 / 10}=0,9$ \\
\hline 12 & $\alpha^{21}{ }_{1 / 12}=0$ & $\alpha^{22}{ }_{1 / 12}=0$ & $\alpha^{23}{ }_{1 / 12}=1,0$ & $\alpha^{24}{ }_{1 / 12}=1,0$ \\
\hline$\ldots$ & $\ldots \ldots$ & $\ldots \ldots$ & $\ldots \ldots$ & $\ldots \ldots$ \\
\hline
\end{tabular}

The values of set measures calculated by formulae (22) and (23) with the use of tables 2 and 3 are presented in Table 4.

Table 4. Measures of sets $F^{U i}{ }_{1}$ for the "Knowledge" descriptor

\begin{tabular}{|c|c|c|c|c|c|c|c|c|}
\hline $\begin{array}{c}\text { Qualifi- } \\
\text { cation level }\end{array}$ & 0 & 1 & 2 & 3 & 4 & $\ldots$ & 8 & 9 \\
\hline $\begin{array}{c}\text { The } \\
\text { NQFU }\end{array}$ & 10,0 & 20,0 & 28,9 & 38,6 & & $\ldots$ & & 92,2 \\
\hline The EQF & & 7,5 & 14,0 & 23,4 & 31,4 & $\ldots$ & 77,1 & \\
\hline
\end{tabular}

Since the Bologna Process gives countries the right to take into account their experience and national traditions in the development of national frameworks, a direct comparison of measures relating to different notions would not be entirely correct. Most countries have used this right, as a result of which, sets for similar notions in different frameworks differ both in the availability of the unit elements $v_{i}$ and in the probability of their inclusion in the sets under consideration. In order to bring the measures of the notions analyzed to one number system (to one scale), we introduce an additional condition. We suppose that the quality of education in all the state members of the Bologna process is the same. In this case, the measure of each of the national framework or the measure of the highest level of qualification for one of the descriptors can be estimated by the same number of points. If the quality of education is not the same, in a particular case, experts may decide to reduce or increase the maximum score.
In our example, the maximum evaluation of the education quality according to the "Knowledge" descriptor at the highest level of qualification, regardless of the number of levels of the national framework, is equal to 100 points. In this case, the scaling of the calculation results of the data presented in Table 4, shows an increase in all measures of Table 4 in $100 / \mu\left(F^{U \max }{ }_{1}\right)$ times, where the index $\max$ corresponds to the highest value of the skill level in the framework with the index $U$. The max values for the NQFU and EQF are 10 and 8 , respectively. According to Table 4:

$$
F_{1}^{2 \max }=F_{1}^{28}=77,1 ; F_{1}^{1 \max }=F_{1}^{19}=92,2
$$

We introduce the following notations for normalized measures:

$$
\mu\left(M^{U i}{ }_{1}\right)=\mu\left(F^{U i}\right) / \mu\left(F_{1}^{U \max }\right)
$$

The results of data scaling from Table 4 with regard to (24) and (25) are given in Table 5.

Table 5. Normalized measures of sets of the "Knowledge" depending on the qualification level in the NQFU and the EQF

\begin{tabular}{|c|c|c|c|c|c|c|c|c|}
\hline $\begin{array}{c}\text { Qualifica- } \\
\text { tion level }\end{array}$ & 0 & 1 & 2 & 3 & 4 & $\ldots$ & 8 & 9 \\
\hline$N^{N i}{ }_{1}, \mathrm{NQFU}$ & 10,8 & 21,7 & 31,3 & 41,8 & & $\ldots$ & $\ldots$ & 100 \\
\hline$N^{U i}{ }_{1}, \mathrm{EQF}$ & & 9,7 & 18,2 & 30,3 & 41,9 & $\ldots$ & 100 & \\
\hline
\end{tabular}

It is evident from Table 5 that levels $0,1,2$ and 3 of the NQFU correlate to levels $0,1,2$ and 3 of the EQF.

Each superior set contains all or at least most of the unit elements belonging to the lower-level sets of qualifications. The maximum rank is estimated at 100 points, so the average difference in measures for neighboring sets for frameworks with 8-10 levels of qualifications is about $10-13$ points. The data of Table 5 proves the point: in the case of the NQFU, the change in the measure from the lower to the higher one is in the range of 9.6-10.9, and in the case of the EQF, it is within 8.5-12.1. Therefore, as a criterion for comparing two sets related to different notions, it is appropriate to use not the measures themselves but their relative differences in percentages

$$
d_{m n}=100\left(M_{\max }-M_{\min }\right) / M_{\max },
$$

where $M_{\max }$ is the largest measure being compared, and $M_{\min }$ is the smallest one.

The value of $d_{m n}$, calculated by the formula (26), characterizes the degree of notion difference. The values of the $d_{m n}$ criterion, depending on the qualification level of the NQFU and the EQF are presented in Table 6 . 
Table 6. Values of the difference criterion dmn of the "Knowledge descriptor" depending on the qualification level of the NQFU $(m=0,1,2,3)$ and the $\operatorname{EQF}(n=1,2,3$.

\begin{tabular}{|c|c|c|c|c|}
\hline $\mathrm{m} / \mathrm{n}$ & $\mathrm{m}=0$ & $\mathrm{~m}=1$ & $\mathrm{~m}=2$ & $\mathrm{~m}=3$ \\
\hline $\mathrm{n}=1$ & $\mathrm{~d}_{01}=10$ & $\mathrm{~d}_{11}=55$ & $\mathrm{~d}_{21}=69$ & $\mathrm{~d}_{31}=77$ \\
\hline $\mathrm{n}=2$ & $\mathrm{~d}_{02}=41$ & $\mathrm{~d}_{12}=16$ & $\mathrm{~d}_{22}=41$ & $\mathrm{~d}_{32}=56$ \\
\hline $\mathrm{n}=3$ & $\mathrm{~d}_{03}=64$ & $\mathrm{~d}_{13}=28$ & $\mathrm{~d}_{23}=3,2$ & $\mathrm{~d}_{33}=28$ \\
\hline $\mathrm{n}=4$ & $\mathrm{~d}_{04}=74$ & $\mathrm{~d}_{14}=48$ & $\mathrm{~d}_{24}=25$ & $\mathrm{~d}_{34}=0,24$ \\
\hline
\end{tabular}

Fig. 2 shows the dependence of the $\mathrm{d}_{\mathrm{mn}}$ criterion of the qualification level $n$ for the EQF at various skill levels of the NQFU.

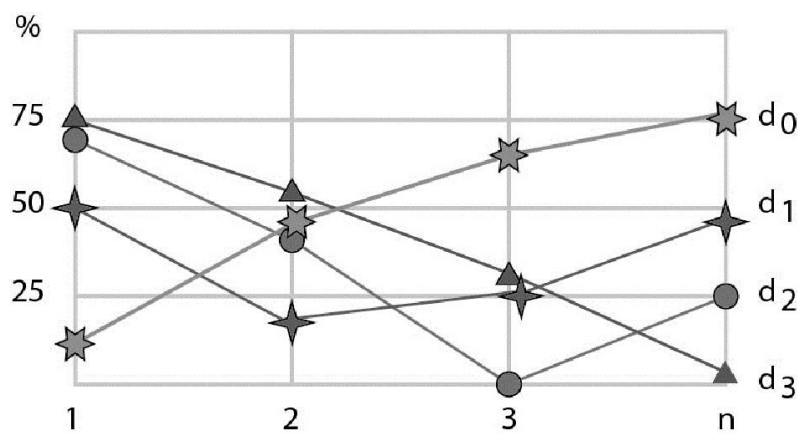

Fig. 2 - Dependence of the $d$ criterion of the qualification level for the EQF at different qualification levels of the NQFU

Fig. 2 and Table 6 prove that the "Knowledge" descriptor of the zero skill level differs from the first level of the EQF by $10 \%$. The difference with the second, third and fourth levels is estimated, respectively, in $41 \%, 64 \%$ and $74 \%$. The same descriptor at the first level differs from the second level descriptor of the EQF by $16 \%$. Descriptors of the second and third levels of the NQFU practically coincide with the descriptors of the third and fourth levels of the EQF respectively.

\section{CONCLUSION}

The proposed model of the intelligent system is based on the concept of knowledge base application in the process of solving various tasks, depending on user needs. Such a system is, as a matter of fact, an expert system. At present there is not any universal body of logics and mathematics which could meet requirements of any $I S$ developer. Our model is developed on the basis of special knowledge related to the classification of European education levels in the context of the Bologna process.

The conceptual construct of the model covers the main elements of the European qualification frameworks. These include:

- the notions of the national qualifications frameworks of different countries: the notion $F^{U}$, $U=1$ (the NQFU), $U=2$ (the EQF), $U=3$ (the NQFR) etc.;
- the notions of qualification levels: the notion $F^{U i}(i=0,1,2, \ldots 9$ for the NQFU; $i=1,2, \ldots 8$ for the EQF; $i=1,2, \ldots 10$ for the NQFR etc.);

- the notions of qualifications descriptors "Knowledge","Skills" et al: the notion $F^{U i}{ }_{k}$ with index $k=1,2, \ldots$

The notions mentioned above have been matched with the sets $F^{U}, F^{U i}, F^{U i}{ }_{k}$ of the unit elements $v_{k}$, that have been defined in the domain $Q$ which characterizes the semantic content of all the frameworks. The initial data is the set $V$ of elementary coded semantic units $v_{k}$ and tables containing $v_{k}$ membership probabilities for the sets $F^{U}, F^{U i}, F^{U i}$.

The proposed algorithm of statistic calculations allows to carry out a comparative analysis of different elements of frameworks. The formulae (10)-(12) determine a numerical measure of each of the sets by measures $v_{k}$. The alternative formulae (13)-(17) allow to solve the same tasks in the presence of additional information about the subsets membership to the senior sets. Original tables are filled by experts. Adequacy of models depends on agreed points of view and expert work. It is estimated using the formulae. The formulae (18)(21) could be used for checking up the model adequacy.

The application example of the $I S$ certifies a rather high correctness of comparison results of the NQFU and EQF qualification levels in the case of the "Knowledge" descriptor.

Any IS model has to be adapted to a user. Our case is no exception. When filling out tables for various national qualifications frameworks and involving experts of different schools there is a possibility of expanding the circle of problems to be solved within the framework of the proposed model. For example, it would seem, in this respect, that it is promising to add supplementary modules to the $I S$ module, this enables to make a comparison of the qualifications framework of one country with another one in terms of the EQF, to implement users self-testing to assess their level of qualification and to solve other tasks.

\section{REFERENCES}

[1] The European Higher Education Area in 2012: Bologna Process Implementation Report, Brussels: Eurydice, 2012, 220 p. [Online]. Availiable: www.eacea.ec.europa.eu/education/ eurydice.

[2] Dublin descriptors. The European qualifications framework of higher education, 2014, [Online]. Availiable: www.tempusrussia.ru/Tem-pus-3call.pdf. 
[3] Yu. M. Rashkevych, The Bologna Process and the New Paradigm of Higher Education, Monograph, Lviv, Lviv Polytechnic University Publishing House, 2014, 168 p. (in Ukrainian).

[4] National Qualifications Framework of Russian Federation, Project of Russian Federation, 2012, [Online]. Availiable: www.narkrspp.ru/?page_id=328. (in Russian).

[5] National Qualifications Framework Developments in Europe. Anniversary Addition, Luxembourg, Publications Office of European Union, 2015.

[6] E. B. Hunt, Artificial Intelligence, New York, San Francisco, London, Academic Press, 1975, $558 \mathrm{p}$.

[7] S. J. Russell, and P. Norvig, Artificial Intelligence, trans. from English, Moscow, Saint Petersburg, Kiev: Williams, 2006, 1408 p. (in Russian)

[8] I. M. Makarov, V. M. Lokhin, Intelligent Automatic Control System, Moscow: Fizmatlit, 2001, 576 p. (in Russian).

[9] D. G. Dosyn, V. V. Lytvyn, Yu. V. Nikolsky, V. V. Pasichnyk, Intelligent Systems Based on Ontologies, Lviv: Civilization, 2009, 414 p. (in Ukrainian).

[10] O. V. Nevmerzhytskyi, "Analysis of modern knowledge-oriented models and decision making methods," Information Technology of Design, vol. 13, pp. 119-125, 2013. (in Ukrainian).

[11] T. A. Gavrilova, V. F. Khoroshevsky, Knowledge Base of Intelligent Systems, St. Petersburg: Piter, 2000, 384 p. (in Russian).

[12] P. Jackson, Introduction to Expert Systems, 3rd edition, Hardbound - Addison Wesley Publishing Company, 1998. 560 p.

[13] P. Domingos, The Master Algorithm: How the Quest for the Ultimate Learning Machine will Remake our World, Moscow: Mann, Ivanov and Ferber, 2016, 336 p. (in Russian)

[14] G. V. Rybina, Theory and Technology of Construction of Integrated Expert Systems, Moscow: Nauchtehlitizdat, 2008, 485 p. (in Russian)

[15] V. V. Lytvyn, R. R. Darewych, D. G. Dosyn, N. V. Shkutiak, "Design of intelligent agents when making decisions in feature space using the ontological approach," Artificial Intelligence, no. 4, pp. 398-403, 2010.

[16] V. V. Osadchy, K. P. Osadcha, S. V. Sharov, V. S. Eremeev, "The concept of intelligent system of information and cognitive support of National Qualifications Framework functioning," Collected Works "Information processing systems", vol. 12 (137), pp. 88-92, 2015. (in Ukrainian).
[17] "National qualifications framework of Ukraine," Resolution of the Cabinet of Ministers of Ukraine, November 23, 2011, no. 1341, Kyiv, [Online]. Available: www.zakon3. rada.gov.ua/laws/show/1341-2011-\%D0\%BF (in Ukrainian).

[18] Order of the Ministry of Labour and Social Protection of the Russian Federation of 22.01.2013, no. 23, "On the approval of skills levels for the development of professional frameworks drafts," [Online]. Available: http://www.rosmintrud.ru/docs/mintrud/orders/ 48. (in Russian).

[19] I. A. Fedorova, "Comparative analysis of the national frameworks of qualification in the higher education area in Russia and European Union," Omsk Scientific Bulletin. Psychological and Pedagogical Aspects of Science, no. 2-86, pp. 143-146, 2010 (in Russian).

[20] R. Thiagarajan, G. Manjunath, M. Stumptner, "Computing semantic similarity using ontologies," in Proceedings of the International Semantic Web Conference (ISWC'08), Karlsruhe, Germany, 2008, [Online]. Available: http://www.hpl.hp.com/techreports/ 2008/HPL-2008-87.pdf.

[21] E. G. M. Petrakis, G. Varelas, A. Hliaoutakis, P. Raftopoulou, "Computing semantic similarity between concepts from different ontologies," Journal of Digital Information Management, vol. 4, issue 4, pp. 233-237, 2006.

[22] S. Vijay, "Combined method to measure the semantic similarity between words," International Journal of Soft Computing and Engineering (IJSCE), vol. 1., issue-ETIC2011, pp. 49-54, 2012.

[23] H.-D. Li, Q.-C. Chen, X.-L. Wang, "A combined measure for text semantic similarity," in Proceedings of the International Conference on Machine Learning and Cybernetics, 2013, vol. 4, pp. 1869-1873.

[24] N. E. Chapaykina, "Semantic analysis of texts. The main provisions," Young Scientist, no. 5, pp. 112-115, 2012. (in Russian).

[25] A. Miroshnichenko, "National qualifications framework in Ukraine," Community of Personnel Officers and Professionals of Human Resources Management, 2010, [Online]. Available: http://hrliga.com/index.php?module $=$ profession $\& o p=$ view\&id $=1251$ Ukrainian). 


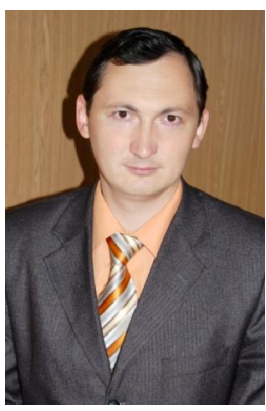

Viacheslav Osadchyi is a Doctor of Pedagogical Science, Professor of Melitopol State Pedagogical University named after Bohdan Khmelnytskyi, Ukraine. He has been working at the university since 1999 and currently he is a head of the Department of Computer Science and Cybernetics.

His research interests are software engineering education and information and communication technologies in teacher education. His skills include development of intelligent systems, expert systems, mathematical modeling, data mining and others.

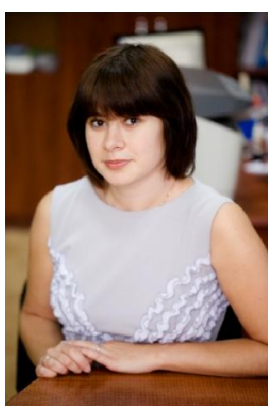

Kateryna Osadcha is a $P h D$ (Pedagogical Science), Associate Professor of Melitopol State Pedagogical University named after Bohdan Khmelnytskyi, Ukraine. She has been working at the university since 2002. She has got a master's degree in computer science.

Her research interests are soft- ware engineering education, Internet technology, distance learning, e-learning. Her skills include development of intelligent systems, expert systems and others.

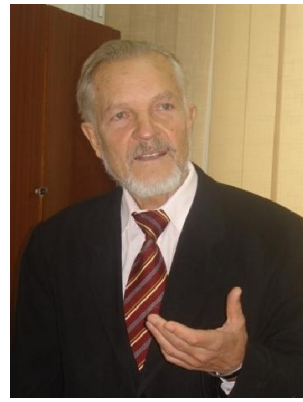

Volodymyr Eremeev is a Doctor of Technical Science, Professor of Melitopol State Pedagogical University named after Bohdan Khmelnytskyi, Ukraine. He has got 55 years of experience in mathematical modeling. He has been working at the university since 1995.

His scientific interests are software development for learning and teaching and data mining. 